\title{
Healthy food is nutritious, but organic food is healthy because it is pure: The negotiation of healthy food choices by Danish consumers of organic food
}

\author{
Kia Ditlevsen*, Peter Sandøe, Jesper Lassen \\ Department of Food and Resource Economics, University of Copenhagen, Denmark
}

\section{A R T I C L E I N F O}

\section{Keywords:}

Organic food products

Consumer preference

Health

Purity

Qualitative research

\begin{abstract}
A B S T R A C T
There is increasing demand for organic food products throughout the Western world. Health concerns have frequently been found to be the main motivation of consumers purchasing organic products, but the literature on consumer preferences and behavior is less clear about what 'health' means to consumers of these products, and because of this it remains unclear what exactly drives consumers to choose organic products. This article investigates health from the perspective of consumers, and analyzes negotiations of, and justifications behind, their consumption preferences. The analysis is based on a focus group study conducted in Denmark in 2016. Three different understandings of health can be found when consumers explain their preferences for organic products: Health as purity; Health as pleasure, and a Holistic perspective on health. The first two are familiar from the literature on food. The third, which reflects principles behind organic agriculture, is less documented in the context of consumption. Health as purity was the dominant understanding of health used by the participants when explaining why they purchased organic food products. When participants discussed healthy eating in general, detached from a specific context, most employed a purely nutritional perspective as a definitive argument in supporting claims about healthy eating. The paper's findings have implications for future research on organic consumption. They also have practical implications for organic food producers and manufacturers.
\end{abstract}

\section{Introduction}

In Denmark, as in many other countries, demand for organic food products has grown over the last few decades. Developments in modern organic food production have been driven largely by the ideal of sustainability and environmental concerns. However, attitudes to production have evolved in a dialogue between producers and consumers, leading to developments in the perceptions of both parties (Lassen \& Korzen, 2009). The non-sensory attributes of food products - in addition to their sensed qualities such as taste and texture - are important to organic consumers (Hjelmar, 2011; Magnusson, Arvola, Hursti, Åberg, \& Sjödén, 2003); and among these non-sensory qualities personal health benefits are now considered to play the most important role in consumers' decisions to opt for organic (Hansen, Sørensen, \& Eriksen, 2018; Apaolaza, Hartmann, D’Souza, \& López, 2018; Rana \& Paul, 2017; Honkanen, Verplanken, \& Olsen, 2006). Studies have found that consumers who prefer organic food often describe both health and environmental concerns as motives behind their choice, but there is also some evidence that an expectation of health gains is the factor most likely to push consumers from a mere preference for organic products to actual purchases of them, overcoming the fact that organic produce is generally more expensive than the conventionally produced alternatives (Denver \& Christensen, 2015).

As far as we have been able to determine, the way consumers themselves perceive and define health in relation to organic food products is overlooked in nearly all studies of consumer attitudes to organic foods. This is surprising, as the concept of health can hardly be said to be free of ambiguity (cf. Bisogni, Jastran, Seligson, \& Thompson, 2012). As a result of this lack of clarity of how consumers understand healthiness, researchers working on organic consumption risk misinterpreting the health claims being made by those who participate in their studies. There is also a wider issue, since if society and food suppliers are to increase the market share of organic food products, it will be important to know precisely why organic foods are in demand.

\subsection{Negotiations and justifications of food preferences}

The consumption of food products is part of everyday life. Food choice is contextual, dynamic and integrated in social life; it is intertwined with practical considerations, family disputes and emotional

\footnotetext{
* Corresponding author at: Section for Consumption, Bioethics and Governance, Department of Food and Ressource Economics, University of Copenhagen, Rolighedsvej, 25, DK-1958 Frederiksberg C, Denmark.

E-mail address: kmd@ifro.ku.dk (K. Ditlevsen).
} 
factors (Sobal, Bisogni \& Jastran, 2014; Christensen, 2004). It is also affected by political reflections and moral debates. People's values, and what they see as 'good' for themselves, their families and society, are enacted in consumption, and therefore if we are to understand the consumption of organic food products we need to investigate how preferences are justified and negotiated (Stamer, 2018; Boltanski \& Thevenot, 1999). Moral norms often underlie consumer activities. Boltanski and Thevenot's $(1999,2000)$ Conventions approach is a framework for studying moral debates carried out in everyday situations in which people face conflicting requirements. In situations where choices are contested, or debated, people are obliged to justify their everyday choices with reference to underlying norms, in an acceptable manner, so that the justification appears sound and relevant to all involved parties (Boltanski \& Thevenot, 1999). The Conventions approach is based on the assumption that people are able to justify their practices, and that in doing so they are able to distinguish between legitimate and illegitimate justifications (Andersen, 2011). Boltanski and Thévenot (2000) claim that justifications are grounded in different, yet common, moral conventions about the worth of practices, persons etc., and that these so-called orders of worth pre-date individuals or social groups and are used to make sense of situations in everyday life. Each order of worth, or regime of justification, has its own internal logic and functions as a repertoire of legitimate justifications which individuals invoke in situations in which their values or practices are contested. It is thus in situations of debate and negotiation between people that it becomes apparent how people use concepts like health to justify their preferences, and this in turn reveals what they associate with these concepts.

Health concerns have been found to be linked to different orders of worth (Stamer, 2018; Andersen, 2011; Truninger, 2011). However, given the ubiquity of health concerns connected with the consumption of organic food as well as general food consumption (Ilmonen, 2011), our study does not assume that healthiness is tied to a specific regime of justification. Hence, rather than using the Conventions approach to link particular understandings of health with specific orders of worth, we will employ the theoretical concepts of the approach to analyze the use of health in negotiations and justifications observed in a group of organic consumers.

\subsection{Consumer understandings of health}

Understandings of health, healthy food and meals, and the contextualization of the concept of health have been investigated in consumer studies and the sociology of food for more than a decade. We have found three distinctive overarching concepts of health to be present in the theoretical as well as the empirical scientific literature - a finding that corresponds to an extent with earlier overviews of the literature (Chrysochou, Askegaard, Grunert, \& Kristensen, 2010). In an attempt to synthesize the literature, we have named the three concepts to reflect their conceptual foundations, i.e. the distinctive way in which the healthiness of food is assessed in them. The concepts are: Health as nutritional value; Health as pleasure; and Health as purity.

\subsubsection{Health as nutritional value}

According to the understanding of health as nutrition, the healthiness of a food product is determined by its nutritional value. This approach is sometimes termed the 'functional discourse' or 'nutritionism', and it is rooted in a biomedical understanding of health and in the scientific discipline of human nutrition (Chrysochou et al., 2010; Bouwman, Te Molder, Koelen, \& van Woerkum, 2009; Pollan, 2008). In light of this understanding, organic food products will be considered healthier than conventional products, if the content is of better nutritional value, perhaps because they have a higher level of essential micronutrients or because they have a better composition of macronutrients (e.g. lower levels of fats) as compared with alternatives.

\subsubsection{Health as pleasure}

According to the second understanding, the healthiness of foods is defined by the sensory pleasure it brings you, and the experience you enjoy while eating it. The logic is that it is healthy to have a 'happy' body, to experience pleasure, and to enjoy food as a part of a social community; and that good quality foods satiate better than food of low quality and thus make one eat less, but better (Fischler, 2011; Vogel and Mol, 2014). This approach, which is sometimes called the 'culinary order', incorporates notions of gastronomy and commensality in our understanding of healthiness (Chrysochou et al., 2010; Fischler, 2011). In this understanding organic food products are healthier than their conventional counterparts if their taste, texture or other sensory characteristics are superior.

\subsubsection{Health as purity}

According to the third understanding, the purity of food is the essential factor when assessing healthiness. In this context purity can be taken to indicate an absence of food additives, preservatives and residues, or the naturalness of a food product (Rozin et al.,2004; Rozin, Fischler, \& Shields-Argeles, 2012; Douglas, 2002). Purity and naturalness are interchangeable concepts: unsullied and untampered-with nature is often viewed as equivalent to purity (Dickson-Spillmann, Siegrist, and Keller, 2011). Thus purity is typically inferred from the absence of pollution (Douglas \& Wildavsky, 1983). From this perspective organic foods are regarded as healthy to the extent that they are uncontaminated and purer than conventional foods - i.e. not altered or polluted by artificial additives or by excessive human interference (Schifferstein \& Oude Ophuis, 1998; Dickson-Spillmann et al., 2011).

\subsection{Aims of this study}

This article asks how health is understood by consumers of organic food products (in short: "organic consumers"). Drawing on a qualitative study conducted in Denmark in 2016, and focusing particularly on understandings of health, it analyzes the way organic consumers justify their own food preferences and negotiate those preferences when choosing to consume organic food products. Specifically, the study objectives were to:

1) Identify different ideas of health present in organic consumers' justifications of their preference for organic food products

2) Understand how the identified ideas of health are used in organic consumers' negotiations of consumption choices

\section{Methods}

Adopting Boltanski and Thevenot's Conventions approach as the point of departure for the empirical analysis, this study explored organic consumers' ideas, justifications and negotiations in focus groups. The focus group method is particularly useful where the aim of research is to examine the ways in which people debate their actions and preferences with others (Halkier, 2016).

\subsection{Participants}

We conducted six focus group interviews, each with five to seven participants. The participants were recruited by a professional bureau through an internet panel, and each of them received 55-85 USD as a token of gratitude for their participation. Most had never participated in a focus group discussion before, and none had participated in one during the last year. The criterion for participation was a preference for organic food. Given the study objectives, it was essential that the participants were in fact consumers of organic products, and that they held opinions and had preferences in relation to their food consumption of a kind that would allow us to investigate their ideas of health. In prescreening, the participants had stated that being organic was either 
Table 1

Focus groups and participants.

\begin{tabular}{|c|c|c|c|c|c|c|}
\hline Focus group & 1 & 2 & 3 & 4 & 5 & 6 \\
\hline Degree of urbanization & Capital & Capital & Provincial city & Rural area & Provincial city/town & Rural area \\
\hline Regional area & Zealand & Zealand & Fyn & Fyn & Jutland & Jutland \\
\hline Number of participants & 5 & 7 & 7 & 7 & 6 & 7 \\
\hline \multirow[t]{2}{*}{ Level of education" } & No: 1 Medium: 3 & No: 1 Vocational:2 & Short: 1 Medium: 4 & No: 1 Vocational: 2 & No: 1 Vocational: 2 & Vocational: 1 Short: 1 \\
\hline & Long: 1 & $\begin{array}{l}\text { Medium:2 Long: } 1 \text { Student: } \\
1\end{array}$ & Long: 2 & Short: 1 Medium: 3 & Short: 1 Medium: 2 & Medium: 3 Long: 2 \\
\hline $\begin{array}{l}\text { Average age of } \\
\text { participants }\end{array}$ & $48[36-57]$ & $49[27-58]$ & $43[27-64]$ & $52[45-62]$ & $48[35-56]$ & $52[38-65]$ \\
\hline Gender of participants & 2 male 3 female & 4 male 3 female & 3 male 4 female & 3 male 4 female & 2 male 4 female & 3 male 4 female \\
\hline
\end{tabular}

$*$ No tertiary training $=$ No; Vocational training/education = Vocational; short-cycle higher education = Short; Medium cycle higher education = Medium; Longcycle higher education $=$ Long.

'very important' or 'important' for choosing a food product while doing grocery shopping. In total 39 adult persons participated, 17 males and 22 females. The average age was 49 years; the youngest and oldest participants were 27 and 65 years old. The focus groups were geographically and demographically mixed (see Table 1 ).

The participants were sampled to ensure that there was variation in economic background, education, age, gender, and degree of urbanization. These are factors known to affect consumer preferences for organic food products (Hjelmar, 2011; Lund, Andersen \& O'Doherty Jensen, 2012; Wier, O’Doherty Jensen, Andersen, \& Millock, 2008). In a further effort to secure sufficient variation of consumer types, the participants were sampled according to three contrasting consumer profiles found among organic consumers in Denmark in an earlier study (Lund et al., 2012): the convinced consumer ('organic' is the most important attribute); the involved consumer ('taste' is the most important attribute); and the pragmatic consumer ('price' and 'availability' is most important). The three profiles were represented in all focus groups in order to ensure that a range of perspectives were heard.

Participants were sampled to ensure that the focus group discussions would not reflect the views of just one kind of organic consumer. Participant characteristics were not found to relate to particular results in relation to the questions analyzed in this article.

The participants' agreement to take part in the focus groups was based on fully informed consent; all participants are anonymized in this report of the study findings.

\subsection{Focus groups}

The focus group discussions were conducted as part of a larger research project on organic consumption and health (OrgHealth, 2017). They were moderated by the first author and lasted two hours each. They were structured using a discussion guide which consisted of a combination of tasks, open-ended group questions initiating the sessions, individual questions for each participant, and follow-up questions for the group. Participants were not interviewed individually during the focus groups, but they were prompted by the moderator's questions and exercises to state their own opinions, and of course to reflect and discuss these with other participants.

In order to investigate ideas of health in consumers' negotiations and justifications of their consumption choices we asked the participants to talk about their motives for preferring organic food products. Beginning with individual preferences, the discussion guide led participants to discuss motives behind consumption, and as a group to prioritize (negotiate) their relative importance. Participants were also asked to talk about a range of situations in which they had to choose in a shopping situation (e.g. between organic imported apples/local apples; local minced meat/organic imported minced meat). This led them to negotiate their way through different aims, with reflections on the importance of health amongst other factors, and to expand on their ideas of health when justifying their choices. Afterwards we asked participants to talk about health: they were asked to define healthiness in general terms, and to discuss whether organic foods are healthier than conventional foods.

\subsection{Analytic approach}

The discussions were recorded and transcribed verbatim, and the material was then thematically coded in NVivo 10 (Halkier, 2016). As a first step of the analysis, the first author coded the focus group transcripts. The third author then reviewed the codes and interpretations of specific extracts from the group discussion in order to validate the reading of the empirical material. Throughout the study the analysis was discussed by all authors. The coding had both a deductive and an inductive phase (David \& Sutton, 2011). The initial coding phase was deductive. It was based on categories derived from operationalization of the study objectives (to investigate justifications and negotiations): ideas of health; motivation to buy organic food; and whether organic food products are healthier. In the course of the data collection and the first readings of the empirical material inductive codes were generated from the data, and different kinds of health concept were added as subcategories in the coding process. The analytical process included a qualitative content analysis of what participants said, but also a categorization and conceptualization in which the codes were connected to each other and the context in which they occurred in the focus group discussion (Halkier, 2016).

Our analyses apply the notions of negotiations and justifications (Boltanski \& Thevenot, 1999) to make it apparent how and when different understandings of health are used in disputes, and when different concepts are considered sound and valid. Conceptually ordered displays combining within-case and cross-case comparisons were made for each focus group (David \& Sutton, 2011). These showed each participant's motivation for buying organic products, the understanding of health that participants expressed throughout the focus group exchanges, and whether they stated that organic products are healthier than conventionally produced products. The collective rankings of motives to buy organic food products which each group made were also included in the displays.

\section{Results}

When the focus group participants presented their individual reasons for preferring organic food products they expressed four recurrent motives (one sensory and three non-sensory): Health concerns, Environmental concerns, Animal welfare, and Taste. In this focus group study, as in most other studies of organic consumers, health was an important driver of consumer choice. Moving on to the content of the concept health, we found that all three overarching health concepts from the literature (see Section 1.2) were articulated in the focus group discussions: Health as nutritional value; Health as pleasure; and Health as purity. All of these focus on health at the level of the individual, one's 
Table 2

Health understandings identified in the focus group discussions.

\begin{tabular}{|c|c|c|c|c|}
\hline & $\begin{array}{l}\text { Health as nutritional } \\
\text { value }\end{array}$ & Health as pleasure & Health as purity & Holistic health \\
\hline Level & $\begin{array}{l}\text { Individual health (micro } \\
\text { level) }\end{array}$ & $\begin{array}{l}\text { Individual health } \\
\text { (micro level) }\end{array}$ & $\begin{array}{l}\text { Individual health (micro } \\
\text { level) }\end{array}$ & $\begin{array}{l}\text { Health of the earth; animals; and humans (micro-, meso- and } \\
\text { macro-level) }\end{array}$ \\
\hline $\begin{array}{l}\text { Qualifying factors for } \\
\text { healthiness }\end{array}$ & $\begin{array}{l}\text { Good nutritional value of } \\
\text { food products }\end{array}$ & $\begin{array}{l}\text { Sensory quality of } \\
\text { food products }\end{array}$ & $\begin{array}{l}\text { Food products free of } \\
\text { contamination }\end{array}$ & $\begin{array}{l}\text { Food products free of contamination }+ \text { environment-, climate- and } \\
\text { animal friendly production }\end{array}$ \\
\hline
\end{tabular}

personal health and the health of one's close relatives. But in addition to these understandings, reflecting the three concepts from the literature, a fourth understanding of health was voiced by the participants: Health in a holistic perspective. In this perspective the 'health' of the earth is connected with the health of individual people (this understanding will be elaborated below and in the Discussion section), thus integrating health at different societal levels (micro, meso, macro). An overview of the identified understandings of health that emerged in the focus group interviews is presented in Table 2. The four understandings were not equally represented in the focus groups; the distribution is dealt with in the Results section.

All but one of these health perspectives were shared by several participants across the focus groups. (Health as pleasure was articulated by only one person). We suggest that they can be seen as common underlying conventions which were available to the participants for use in negotiations, expressing different qualifying factors by which healthiness is assessed (cf. Boltanski \& Thevenot, 1999).

In what follows we will present findings illuminating the ways in which health perspectives were used in justifications of preferences for organic food products by the participants in the focus groups. We will explain how perspectives on health often shift when consumers debate other aspects of consumption, and thus how different conventions are used in different situations. The findings will be discussed in the Discussion section.

\subsection{Understandings of health and the preference for organic food}

Focusing on the first of this study's objectives, to identify different ideas of health in consumers' articulations of their preference for organic food products, we will now take a closer look at how participants in the focus groups explained why they bought organic products. We will analyze the content of health used in these explanations.

The following extract from focus group 5, in which reasons for preferring organic are indicated by Nina and Anna, shows the importance of health concerns:

Nina: Health. That's how you can do something to take care of yourself. And again - we don't know what it [conventionally produced food] contains of toxins and how it will affect us in the future. In fact, that's the main reason that I buy organic food. I am not sure there is scientific evidence for it, but I am sure that you avoid toxins and drug residues when doing so.

Anna: Well, it is the same for me: Health. I believe that organic products are healthier.

In this exchange health is understood as the absence of (chemical) toxins and drug residues and connected with organic production and consumption. Organic food products are seen as uncontaminated. Where other foods are concerned, contamination is considered a health risk by many of the participants. Since organic agriculture involves no use of pesticides and other chemicals, and a restriction on the use of antibiotics in farm animals, organic products are seen as a safer choice. Conventionally produced foods are conceived of as 'unclean' products, and hence a risky choice. The health risk associated with being unclean was often described in a somewhat diffuse way, as in the extract below:

Laila: So I am thinking... what are we eating? If you buy organic, at least something is discarded. I see how more and more people are having fertility problems and more and more get allergies and get sick from something undefined.

The risk of unclean food and a fear of personal contamination were frequently shared in the focus groups, and the health concept expressed here is similar to the Health as purity perspective found in literature. This understanding was by far the most common one expressed when preferences for organic food were explained and discussed in terms of health by the participants.

A holistic perspective on health was brought up in a few focus group discussions. On this understanding of health, individual human 'health' is intimately bound up with environmental health and animal health. Thus Christian, in a discussion in focus group 4, said:

Christian: I buy organic because I believe that it is the only way to put together environment, animals and humans in a proper manner. And of course to avoid chemicals in our water - despite the fact that our politicians tell us it's overrated to be able to drink tap water. But really, in my opinion, we have to hand a proper world over to our grandchildren.

Rather than seeing environmental concerns, animal welfare and individual health as distinct issues, participants like Christian depict them as interlinked parts of a cycle. In a discussion in focus group 5 about the relative importance of health, the environment and animal welfare as reasons for preferring organic foods, the interlinkage between health at different levels and the cyclic aspect were highlighted:

Anna: I think environment should be placed higher...

Nanna: ...If there is not a proper animal welfare...

Anna: If the environment is suffering, there will be no animals!

Nanna: Exactly. And if there is no animal welfare, then we will have polluted food and not very much healthiness.

Helle: Yes, if you use a lot of pesticides and fertilizer, then you will put it in the animals as well. So it is more like a circle than a ranking.

The holistic understanding of health is seldom used in the focus group participants' individual justifications of their consumption preferences, but in the group negotiations of motives and preferences it is used to negotiate the relative importance of these motives, as in the extract above.

Taste is a regularly voiced motive for preferring organic food among the participants in this study, but it is related to health in just one case, where food quality is related to its healthiness, thus echoing the Health as pleasure concept. Health as pleasure therefore appears to be a marginal health perspective in organic consumers' motivations of their preference for organic food products. Jim articulated this perspective when he linked the pleasure of a good meal and health:

Jim: Of course, there has to be a reasonable relation between different nutrients, but for me it is also important that the food tastes of something. That it is appetizing. And that it brings pleasure to the table. The mental aspect of sitting around the table with family and friends and having nice meals... it goes far beyond those food pyramids and nutritional guidelines!

Jim says organic food is a "logical choice" in the same way that avoiding highly processed food products and not smoking is. He did not 
reflect on the matter much in his everyday life, he said, but the other participants' use of health concepts contesting his belief prompted him to justify his practice with reference to a contrasting, underlying health perspective. He prefers quality whole foods because he values the joy of eating and wants to avoid additives, and in his opinion, organic food often secured both of these aims. In Jim's justification of his consumption preferences it was the link with food quality which tied organic food to health.

In the course of the focus group discussions the remaining concept of health found in literature, Health as nutritional value, did not figure in participants' explanations of their motivations for preferring organic food. Still, it played an important role in other contexts, as will now be explained.

\subsection{Negotiations and justifications of consumer choice}

In the discussions of preferences for organic food Health as purity is the most common perspective. However, it was not the most often used convention in other situations, and it did not dominate the exchanges of views in more general discussions of health. To bring this out, we will focus on the second study objective - i.e. that of understanding how different ideas of health are used by participants in discussions of consumer choices by investigating the situations in which the different understandings are used, and how they are used. Here, 'situations' refers to the specific thematic context in the focus group discussion in which different understandings of health were used. The use of the concepts of negotiation and justification to show how different understandings of health are used in situations of dispute will help us to see how the understandings are used to justify specific positions and whether these positions are considered sound and valid by the other participants.

In several focus group sessions, it was possible to detect what seems to be a paradox: asked about organic food consumption, many participants referred spontaneously to its health benefits as a reason to purchase organic foods, but later, when they were prompted to discuss whether organic food is healthier than conventional food, most of them stated that it was not. The explanation of this seeming paradox is that the participants apply different understandings of health in the two contexts. When related to organic products, health is viewed in the Health as purity perspective. From this perspective organic products are considered the healthier choice. By contrast, when the participants were prompted to discuss healthiness in general, they adopt the Health as nutritional value perspective, and viewing matters in this way they conclude that organic products are no healthier than conventional products. Between facing the question on preferences for organic products and the question on the healthiness of organic products, the participants had discussed how to define healthy food in general. In these negotiations the nutritional perspective on health was broadly taken as the definitive concept, as can be seen in this exchange of views from focus group 3 :

Sally: When I think of healthy foods, I think of that food pyramid, right... And I think of how I prepare the food, right, and how I combine it. And then I think that there should be more vegetables than meat, and we don't get gravy anymore.

Tom: I will say: a lot of greens. And fish, we prioritize that at home. Not too much red meat and not too much processed food. And not too much salt.

Eva: I do not have much to add to what has already been said. For me, healthiness is something about a varied diet with vitamins, vegetables and fat... I am not afraid of fat, but I consider which kind of fat I use for cooking.

Healthy food is assessed in terms of its nutritional value when this understanding of health is applied, and biomedical measures (e.g. calories, fiber and vitamin content, the right combination of macronutrients, etc.) are recognized as qualifying factors. When assessing health in these terms, most of the participants did not consider organic food products to be healthier. Further, when this understanding of health enters into the discussion by the moderator's question about healthy food in general, it appears to become the dominant perspective - the perspective, in other words, by which health is defined from that point forward, despite earlier negotiations and justifications in which other understandings of health were in play.

For many participants, the other understandings of health came to seem less useful or legitimate when the understanding of Health as nutritional value was introduced into the discussion. This does not mean that this understanding is wholly uncontested, as can be seen in the interview extract below. Consider how Martin attempts to use Health as purity as a justification for the health benefits of organic products in this negotiation in focus group 1 but is overruled by Mia and Lisa, who apply a nutritional understanding as justification:

Interviewer: Is organic food healthier than non-organic food?

Mia: No

Interviewer: No. Why not?

Mia: No, because routinely there are launched research results, every five years or so, and they have not been able to prove that it is healthier.

Martin: It depends. Nutritional value is different from additivevalue...

Mia: ...But you cannot prove that it is better for your body...

Lisa: I think she is right, actually!

Mia: The ones eating organic, they do not live longer and they are no less sick. There is simply no evidence yet. There is no research proving it.

As the discussion continues Martin ends his argument by declaring that an organic product must be healthier than a non-organic one because it does not infuse the human body with pesticides, but he fails to convince his fellow participants. The same negotiation pattern emerged in other group discussions, where the point of departure is Health as nutritional value and where lack of scientific evidence was the key argument against organic food's health benefits. This argument is not challenged (except by one participant in group 6), but during the discussion the Health as purity perspective is re-introduced as a factor adding to the complexity. This illustrates how different understandings of health are used as justifications by participants and situations in which they are considered valid and sound by other participants. Further, it suggests that Health as nutritional value, once introduced in negotiations, often ends up being a dominant convention, with scientific proof and biomedical evidence being used as definitive arguments.

Expanding the analysis to all four identified understandings of health, we found that when the participants explain their motivation for preferring organic foods, they tend to rely on the convention of the purity perspective. That perspective therefore appears to be an acceptable justification for individual preferences and choices of organic foods over conventionally produced foods. The holistic perspective is mostly used in more abstract discussions of the qualities of organic food, where it is detached from the participants' own individual choices. Here it appears to be a legitimate underlying convention, and one that is also shared by the participants who did not refer to it in justifying their own reasons for choosing organic foods. The pleasure perspective on health, as has been mentioned, is marginalized in the discussions, and we are not able to assess its acceptability as justification. However, when, on occasion, this understanding of health is used to justify behavior or opinions, it is in a debate on individual food preferences. The nutritional perspective is widely used in negotiations on healthy food in general. While it is absent in negotiations of organic food preferences and the qualities of organic products, this convention enjoys wide acceptance and is generally regarded as objective and definitive in assessments of the healthiness of what we eat. The contexts of participants' applications of the different understandings of health, and what those understandings are generally used to justify, are summarized in Table 3. 
Table 3

Perspectives of health in negotiations on organic food and health.

\begin{tabular}{|c|c|c|}
\hline Perspective & $\begin{array}{l}\text { Occurs most often in } \\
\text { situations of }\end{array}$ & Used to justify \\
\hline $\begin{array}{l}\text { Health as nutritional } \\
\text { value }\end{array}$ & $\begin{array}{l}\text { Debates on healthy foods in } \\
\text { general }\end{array}$ & $\begin{array}{l}\text { Objective assessments of } \\
\text { food quality }\end{array}$ \\
\hline Health as purity & $\begin{array}{l}\text { Debates on preferences for } \\
\text { organic foods }\end{array}$ & $\begin{array}{l}\text { Individual actions; } \\
\text { Qualities of organic food }\end{array}$ \\
\hline Health as pleasure & Debate on food preferences & Individual action \\
\hline Holistic health & $\begin{array}{l}\text { Debates on relations } \\
\text { between health and } \\
\text { environment }\end{array}$ & Qualities of organic food \\
\hline
\end{tabular}

\section{Discussion}

In an analysis of organic food and moralities of food provisioning among Danish consumers, Andersen (2011) found that justifications for buying organic food mix arguments from different moral conventions. The same kind of complexity is present in the results presented above, where the four identified health perspectives can be seen as conventions with distinct criteria for evaluating the healthiness of a food product. The conventions were used in different situations, which suggests that their legitimacy is contextual rather than universal, as those terms are defined in the theoretical approach developed by Boltanski and Thévenot (2000).

\subsection{The holistic perspective and individualized consumption}

In our study the holistic perspective on health was not very salient in the discussions of individual preferences for organic products despite the fact that this understanding of health is strongly represented in the principles behind the organic movement. In this movement health in soil, plant, animal and man are regarded as one and indivisible (Howard, 1947; IFOAM, 2017). The holistic perspective combines the fear of contamination of individuals with the fear of contamination of the environment in its cyclical picture of the interlinkage between human health, animal welfare and the 'health of the environment'. A recent American study found that a group of consumers participating in alternative food networks were motivated by a holistic perspective similar to the one in this study, challenging the sharp divide between egoistic and altruistic motivations often found in the literature on organic consumption (Schrank \& Running, 2016). However, among the participants in focus groups in our study individual effects of contamination were singled out as decisive. This finding is in line with recent research from Denmark and Germany. This research indicates that while environmental concerns are the driving preferences of a relatively small group of highly reflexive and politically motivated consumers, other groups of consumers are motivated in their choices by other, individual concerns (Hjelmar, 2011; Grauel, 2014). A study by Stamer (2018) using the Convention approach found that people with high levels of cultural capital (defined by educational level, cultural activities and number of books in household), women, and older people, were all more likely to justify food purchases by referring to the common good (e.g. preserving the health of the environment) than other groups. Our results cannot be used to assess whether social differentiation interacts with justifications, and clearly the connection between conventions and social background needs more exploration.

In contrast with the holistic perspective, the focus on individual health present in the Health as purity perspective aligns well with the tendency toward individualization seen in Western societies (Beck, 1993), where the most common focus for consumers is the environmental issues 'in here', rather than 'out there', according to sociological theory (Bauman, 2012; Macnaghten, 2003). This implies a privatized responsibility for one's body and health, and an awareness of the need to avoid impure products. Environmental concerns are in this sense embodied, and anxiety about the environment becomes disquiet at the prospect of contamination of one's own body (Connolly \& Prothero, 2008). In this light, in situations where an individual's consumption of organic food is to be justified, Health as purity appears to be a more legitimate convention, as it reflects a repertoire of justifications aligned with a common understanding of environmental risk and individual responsibility.

\subsection{Biomedical domination and the nutritional perspective}

In other situations, the Purity perspective was occluded by other perspectives. Most participants did not consider purity an appropriate measure when the theme was health in general terms, detached from organic food consumption. Nutritional measures were widely taken to be the foundation of an objective assessment of food quality, and participants who disagreed found this hard to dispute. Nutritional qualities formed the dominant repertoire of legitimate justifications. This reflects the dominance of nutritional science and the biomedical world view in the public agenda, as has been suggested by critical scholars from different disciplines (Pollan 2008; Lupton, 2012).

This finding echoes familiar debates in the popular media over the healthiness of organic products in which consumer perceptions are often represented as mistaken when they depict organic foods as products with health benefits (e.g. The Guardian, 2016; Vox, 2015; Watson, 2012). Here, a biomedical perspective on evidence and a nutritional understanding of health are used as a definitive measurement by which alleged health benefits are dismissed and lay people's perceptions are considered erroneous. Given the results of our study, this debate appears to be missing the point: the participating consumers are well aware of the scientific evidence on nutrition, but still hold organic food to be healthier, using a different understanding of health as the underlying convention. Our study shows that consumers do in fact demand health, but in the sense given by organic food production: pure food products, free from drug residues, toxins, pesticides and artificial additives.

\subsection{Purity and fear of pollution}

Our findings show that organic food products were perceived as pure, while conventionally produced foods were seen as potentially 'polluted' with the above-mentioned drug residues, toxins, pesticides and artificial additives, and hence as posing health risks. This echoes Douglas \& Wildavsky's (1983:10) point that there is widespread concern about environmental pollution leading to personal contamination, as expressed in people's fear of the "food they eat, the water they drink, the air they breathe". According to Douglas (2002) purity and pollution have a cultural importance in most societies which expands the notions of consumption choice and food preference. Pollution of different kinds has in most cultures been interpreted as a threat to the normality of things, and impurity is considered dangerous, as something implying moral transgression (Douglas, 2002; Douglas \& Wildavsky, 1983). Applying Douglas and Wildavsky's theoretical suggestions to the empirical results of the present qualitative investigation, we can see the fear of personal contamination resulting in preferences for purity of food products, as related to, and enforced by, a cultural narrative of impurity. In this narrative, impurity is understood as a dangerous interference with nature. In a societal context, where citizens are constantly exposed to information about environmental risks, pollution and food safety (Beck, 1993; Connolly \& Prothero, 2008), organic food products become an accessible refuge from the fear of personal contamination (impurity).

\section{Conclusion}

In this study we found three different understandings of health in consumers' justifications of their preference for organic food products: 
Table 4

Summary of findings.

\begin{tabular}{|c|c|c|c|c|}
\hline & $\begin{array}{l}\text { Health as nutritional } \\
\text { value }\end{array}$ & Health as pleasure & Health as purity & Holistic health \\
\hline Level & $\begin{array}{l}\text { Individual health (micro } \\
\text { level) }\end{array}$ & $\begin{array}{l}\text { Individual health } \\
\text { (micro level) }\end{array}$ & $\begin{array}{l}\text { Individual health (micro } \\
\text { level) }\end{array}$ & $\begin{array}{l}\text { Health of the earth; animals; and humans (micro-, meso- and } \\
\text { macro-level) }\end{array}$ \\
\hline $\begin{array}{l}\text { Qualifying factors for } \\
\text { healthiness }\end{array}$ & $\begin{array}{l}\text { Good nutritional value of } \\
\text { food products }\end{array}$ & $\begin{array}{l}\text { Sensory quality of } \\
\text { food products }\end{array}$ & $\begin{array}{l}\text { Food products free of } \\
\text { contamination }\end{array}$ & $\begin{array}{l}\text { Food products free of contamination }+ \text { environment-, climate- } \\
\text { and animal friendly production }\end{array}$ \\
\hline $\begin{array}{l}\text { Occurs most often in } \\
\text { situations of }\end{array}$ & $\begin{array}{l}\text { Debates on healthy foods } \\
\text { in general }\end{array}$ & $\begin{array}{l}\text { Debate on food } \\
\text { preferences }\end{array}$ & $\begin{array}{l}\text { Debates on preferences for } \\
\text { organic foods }\end{array}$ & Debates on relations between health and environment \\
\hline Used to justify & $\begin{array}{l}\text { Objective assessments of } \\
\text { food quality }\end{array}$ & Individual action & $\begin{array}{l}\text { Individual actions; Qualities } \\
\text { of organic food }\end{array}$ & Qualities of organic food \\
\hline
\end{tabular}

Health as purity; Health as pleasure, and a Holistic perspective on health. Health as purity was found to be the most common understanding of health among the participants when health was being discussed in relation to organic consumption. Here it appeared to be regarded as a valid argument for individual preferences for organic products, but when the discussion moved on to a wider discussion of healthy eating it lost that legitimacy. When discussing healthy food in general, in detachment from any specific context, a purely nutritional perspective on health was used and biomedical measures gained relevance as definitive arguments in the debates. Results are summarized in Table 4.

\subsection{Implications for future research}

The results indicate that different understandings of health are used in different situations by consumers. So far as consumer research is concerned, this suggests a need to specify the concept of health in future research: 'health' is likely to be interpreted differently according to the context of the question asked, as well as the situation in which it is understood by the research participants. The present study shows that 'health' is likely to be understood in nutritional terms when it is presented as an abstract term, but in terms of purity when it is raised in connection with organic consumption.

\subsection{Implications for food producers and manufacturers}

Most of the consumers of organic food products participating in this study preferred organic food because, to them, it represented health qualities connected with organic principles - in other words, organic status guaranteed that the purchased food would be free from external contamination by drug residues and pesticides. Hence organic food producers and manufacturers seem to supply products in accordance with consumer demand.

\section{Acknowledgements}

This study is part of the interdisciplinary OrgHealth research project carried out by researchers from Department of Food and Resource Economics at the University of Copenhagen. The research was funded by the Organic RDD 2.2 program, coordinated by ICROFS, International Centre for Research in Organic Food systems. The authors would like to thank our colleagues from the project and the OrgHealth expert monitoring group for useful and constructive comments during various phases of the research. Also we would like to thank Paul Robinson for his assistance in improving our English.

\section{References}

Andersen, A. H. (2011). Organic food and the plural moralities of food provisioning. Journal of Rural Studies, 27(4), 440-450. http://dx.doi.org/10.1016/J.JRURSTUD. 2011.07.004.

Apaolaza, V., Hartmann, P., D'Souza, C., \& López, C. M. (2018). Eat organic - Feel good? The relationship between organic food consumption, health concern and subjective wellbeing. Food Quality and Preference, 63, 51-62. http://dx.doi.org/10.1016/J. FOODQUAL.2017.07.011.
Bauman, Z. (2012). Liquid modernity. Cambridge: Polity Press.

Beck, U. (1993). Risk society, towards a new modernity. (U. Beck, Ed.) (Reprint). London: Sage.

Bisogni, C. A., Jastran, M., Seligson, M., \& Thompson, A. (2012). How people interpret healthy eating: contributions of qualitative research. Journal of Nutrition Education and Behavior, 44(4), 282-301. http://dx.doi.org/10.1016/j.jneb.2011.11.009.

Boltanski, L., \& Thevenot, L. (1999). The sociology of critical capacity. European Journal of Social Theory, 2(3), 359-377.

Boltanski, L., \& Thévenot, L. (2000). The reality of moral expectations: A sociology of situated judgement. Philosophical Explorations, 3(3), 208-231. http://dx.doi.org/10. 1080/13869790008523332.

Bouwman, L. I., Te Molder, H., Koelen, M. M., \& van Woerkum, C. M. J. (2009). I eat healthfully but I am not a freak. Consumers' everyday life perspective on healthful eating. Appetite, 53(3), 390. http://dx.doi.org/10.1016/j.appet.2009.08.005.

Christensen, P. (2004). The health-promoting family: A conceptual framework for future research. Social Science \& Medicine, 59(2), 377-387. http://dx.doi.org/10.1016/j. socscimed.2003.10.021.

Chrysochou, P., Askegaard, S., Grunert, K. G., \& Kristensen, D. B. (2010). Social discourses of healthy eating. A market segmentation approach. Appetite, 55(2), 288. http://dx.doi.org/10.1016/j.appet.2010.06.015.

Connolly, J., \& Prothero, A. (2008). Green consumption. Journal of Consumer Culture. http://dx.doi.org/10.1177/1469540507086422.

David, Matthew, \& Sutton, C. D. (2011). Social research. An introduction (3rd ed.). London: Sage Publications.

Denver, S., \& Christensen, T. (2015). Organic food and health concerns: A dietary approach using observed data. NJAS - Wageningen Journal of Life Sciences. http://dx.doi. org/10.1016/j.njas.2015.05.001.

Dickson-Spillmann, M., Siegrist, M., \& Keller, C. (2011). Attitudes toward chemicals are associated with preference for natural food. Food Quality and Preference, 22(1), 149-156. http://dx.doi.org/10.1016/j.foodqual.2010.09.001.

Douglas, M. (2002). Purity and danger, an analysis of the concepts of pollution and taboo (Routledge). London: Routledge.

Douglas, M., \& Wildavsky, A. (1983). Risk and culture - An essay on the selection of technological and environmental dangers. Berkeley; Los angeles; London: University of California Press.

Fischler, C. (2011). Commensality, society and culture. Social Science Information, 50(3-4), 528-548.

Grauel, J. (2014). Being authentic or being responsible? Food consumption, morality and the presentation of self. Journal of Consumer Culture, 16(3), 852-869. http://dx.doi. org $/ 10.1177 / 1469540514541880$.

The Guardian (2016): "Is organic food healthier?", https://www.theguardian.com/ lifeandstyle/2016/feb/22/is-organic-food-healthier.

Halkier, B. (2016). Fokusgrupper (3. udgave ed.). Frederiksberg: Samfundslitteratur

Hansen, T., Sørensen, M. I., \& Eriksen, M.-L. R. (2018). How the interplay between consumer motivations and values influences organic food identity and behavior. Food Policy, 74, 39-52. http://dx.doi.org/10.1016/J.FOODPOL.2017.11.003.

Hjelmar, U. (2011). Consumers' purchase of organic food products. A matter of convenience and reflexive practices. Appetite, 56(2), 336-344. http://dx.doi.org/10. 1016/j.appet.2010.12.019.

Honkanen, P., Verplanken, B., \& Olsen, S. O. (2006). Ethical values and motives driving organic food choice. Journal of Consumer Behaviour, 5(5), 420-430. http://dx.doi. org/10.1002/cb.190.

Howard, A. (1947). The soil and health, a study of organic agriculture (Culture of the land). Lexington: University Press of Kentucky.

IFOAM (2017): Principles of organic agriculture: https://www.ifoam.bio/en/organiclandmarks/principles-organic-agriculture.

Ilmonen, K. (2011). A social and economic theory of consumption. Basingstoke: Palgrave Macmillan.

Lassen, J., \& Korzen, S. (2009). The environment overlooked? L'environnement est-il négligé? Le rôle des préoccupations environnementales dans les discours sur l'alimentation bio. Anthropology of Food.

Lund, Thomas Bøker; Laura Andersen \& Katherine O’Doherty Jensen (2012): The emergence of diverse organic consumers: Who are they and how do they shape demand? FOI Working Paper/2012(5).

Lupton, D. (2012). Medicine as culture: Illness, disease and the body (3rd ed.). London: SAGE Publications.

Macnaghten, P. (2003). Embodying the environment in everyday life practices 1 . Sociological Review, 51(1), 63-84. http://dx.doi.org/10.1111/1467-954X.00408.

Magnusson, M. K., Arvola, A., Hursti, U.-K. K., Åberg, L., \& Sjödén, P.-O. (2003). Choice of 
organic foods is related to perceived consequences for human health and to environmentally friendly behaviour. Appetite, 40(2), 109-117.

OrgHealth (2017): http://icrofs.dk/forskning/dansk-forskning/organic-rdd-22/ orghealth/.

Pollan, M. (2008). In defense of food, an eater's manifesto. New York: Penguin Press.

Rana, J., \& Paul, J. (2017). Consumer behavior and purchase intention for organic food: A review and research agenda. Journal of Retailing and Consumer Services, 38, 157-165. http://dx.doi.org/10.1016/J.JRETCONSER.2017.06.004.

Rozin, P., Fischler, C., \& Shields-Argeles, C. (2012). European and American perspectives on the meaning of natural. (Report). Appetite, 59(2), 448.

Rozin, P., Spranca, M., Krieger, Z., Neuhaus, R., Surillo, D., Swerdlin, A., \& Wood, K. (2004). Preference for natural: Instrumental and ideational/moral motivations, and the contrast between foods and medicines. Appetite, 43(2), 147-154.

Schifferstein, H. N. J., \& Oude Ophuis, P. A. M. (1998). Health-related determinants of organic food consumption in the Netherlands. Food Quality and Preference, 9(3), $119-133$.

Schrank, Z., \& Running, K. (2016). Individualist and collectivist consumer motivations in local organic food markets. Journal of Consumer Culture, 18(1), 184-201. http://dx. doi.org/10.1177/1469540516659127.

Sobal, J., Bisogni, C. A., \& Jastran, M. (2014). Food choice is multifaceted, contextual, dynamic, multilevel, integrated, and diverse. Mind, Brain, and Education, 8(1), 6-12. http://dx.doi.org/10.1111/mbe.12044.

Stamer, N. B. (2018). Moral conventions in food consumption and their relationship to consumers' social background. Journal of Consumer Culture, 18(1), 202-222. http:// dx.doi.org/10.1177/1469540516668224.

Truninger, M. (2011). Cooking with Bimby in a moment of recruitment: Exploring conventions and practice perspectives. Journal of Consumer Culture, 11(1), 37-59. http:// dx.doi.org/10.1177/1469540510391221.

Vogel, E., \& Mol, A. (2014). Enjoy your food: On losing weight and taking pleasure. Sociology of Health \& Illness, 36(2), 305-317. http://dx.doi.org/10.1111/1467-9566. 12116.

Vox (2015): "Is organic food any healthier? Most scientists are still skeptical", https:// www.vox.com/2014/7/16/5899347/organic-produce-debate-healthier-morenutritious.

Watson, Stephanie (2012): "Organic food no more nutritious than conventionally grown food", in Harvard Health Blog: https://www.health.harvard.edu/blog/organic-foodno-more-nutritious-than-conventionally-grown-food-201209055264.

Wier, M., O'Doherty Jensen, K., Andersen, L. M., \& Millock, K. (2008). The character of demand in mature organic food markets: Great Britain and Denmark compared. Food Policy, 33(5), 406-421. http://dx.doi.org/10.1016/j.foodpol.2008.01.002. 